\title{
Effect of Mg doping on the structural and free- charge carrier properties of InN
}

Mengyao Xie, Ben Sedrine, L. Hong, Bo Monemar, S. Schöche, T. Hofmann, M. Schubert, X

Wang, A. Yoshikawa, K. Wang, T. Araki, Vanya Darakchieva and Y. Nanishi

\section{Linköping University Post Print}

\section{Tweet}

N.B.: When citing this work, cite the original article.

Original Publication:

Mengyao Xie, Ben Sedrine, L. Hong, Bo Monemar, S. Schöche, T. Hofmann, M. Schubert, X Wang, A. Yoshikawa, K. Wang, T. Araki, Vanya Darakchieva and Y. Nanishi, Effect of Mg doping on the structural and free-charge carrier properties of InN, 2014, Journal of Applied Physics, (115), 16, 163504. http://dx.doi.org/10.1063/1.4871975

Copyright: American Institute of Physics (AIP) http://www.aip.org/

Postprint available at: Linköping University Electronic Press http://urn.kb.se/resolve?urn=urn:nbn:se:liu:diva- 85564 


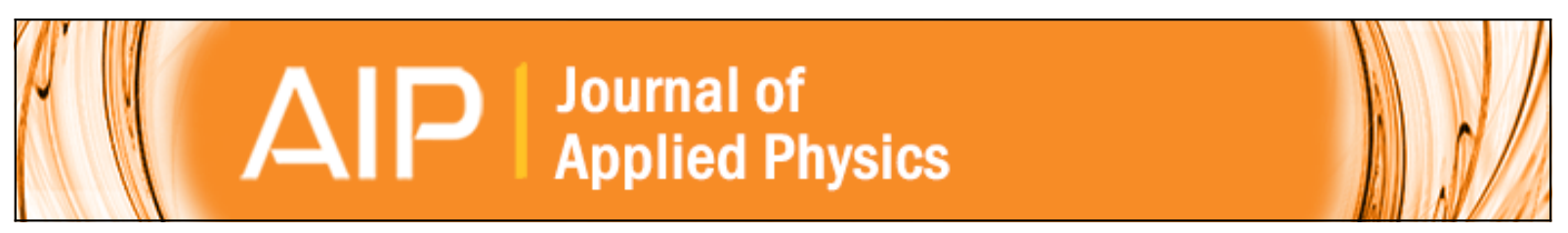

\section{Effect of Mg doping on the structural and free-charge carrier properties of InN films}

M.-Y. Xie, N. Ben Sedrine, S. Schöche, T. Hofmann, M. Schubert, L. Hung, B. Monemar, X. Wang, A. Yoshikawa , K. Wang, T. Araki, Y. Nanishi, and V. Darakchieva

Citation: Journal of Applied Physics 115, 163504 (2014); doi: 10.1063/1.4871975

View online: http://dx.doi.org/10.1063/1.4871975

View Table of Contents: http://scitation.aip.org/content/aip/journal/jap/115/16?ver=pdfcov

Published by the AIP Publishing

\section{Articles you may be interested in}

Infrared to vacuum-ultraviolet ellipsometry and optical Hall-effect study of free-charge carrier parameters in Mgdoped InN

J. Appl. Phys. 113, 013502 (2013); 10.1063/1.4772625

Carrier recombination processes in Mg-doped N-polar InN films

Appl. Phys. Lett. 98, 181908 (2011); 10.1063/1.3586775

$\mathrm{Mg}$ doped InN and confirmation of free holes in InN

Appl. Phys. Lett. 98, 042104 (2011); 10.1063/1.3543625

Effect of stress and free-carrier concentration on photoluminescence in $\ln N$

Appl. Phys. Lett. 92, 121913 (2008); 10.1063/1.2899941

Growth and properties of Mg-doped In-polar InN films

Appl. Phys. Lett. 90, 201913 (2007); 10.1063/1.2741124

\section{AlP Re-register for Table of Content Alerts}




\title{
Effect of Mg doping on the structural and free-charge carrier properties of InN films
}

\author{
M.-Y. Xie, ${ }^{1}$ N. Ben Sedrine, ${ }^{1}$ S. Schöche ${ }^{2}$ T. Hofmann, ${ }^{2}$ M. Schubert ${ }^{2}$ L. Hung, ${ }^{1}$ \\ B. Monemar, ${ }^{1}$ X. Wang,${ }^{3}$ A. Yoshikawa,${ }^{4,5}$ K. Wang,${ }^{6}$ T. Araki, ${ }^{6}$ Y. Nanishi, ${ }^{6,7}$ \\ and V. Darakchieva ${ }^{1, a)}$ \\ ${ }^{1}$ Department of Physics, Chemistry, and Biology, IFM, Linköping University, SE-581 83 Linköping, Sweden \\ ${ }^{2}$ Center for Nanohybrid Functional Materials, Department of Electrical Engineering, University of \\ Nebraska-Lincoln, Lincoln, Nebraska 68588-0511, USA \\ ${ }^{3}$ State Key Laboratory of Artificial Microstructure and Mesoscopic Physics, Peking University, Beijing, China \\ ${ }^{4}$ Center for SMART Green Innovation Research, Chiba University, Chiba, Japan \\ ${ }^{5}$ Department of Information and Communication Engineering, Kogakuin University, Tokyo, Japan \\ ${ }^{6}$ Department of Photonics, Ritsumeikan University, 1-1-1 Noji Higashi, Kusatsu, Shiga 525-8577, Japan \\ ${ }^{7}$ WCU Hybrid Materials Program, Department of Materials Science and Engineering, Seoul National \\ University, Seoul 151-744, South Korea
}

(Received 22 January 2014; accepted 9 April 2014; published online 22 April 2014)

\begin{abstract}
We present a comprehensive study of free-charge carrier and structural properties of two sets of InN films grown by molecular beam epitaxy and systematically doped with $\mathrm{Mg}$ from $1.0 \times 10^{18} \mathrm{~cm}^{-3}$ to $3.9 \times 10^{21} \mathrm{~cm}^{-3}$. The free electron and hole concentration, mobility, and plasmon broadening parameters are determined by infrared spectroscopic ellipsometry. The lattice parameters, microstructure, and surface morphology are determined by high-resolution X-ray diffraction and atomic force microscopy. Consistent results on the free-charge carrier type are found in the two sets of InN films and it is inferred that $p$-type conductivity could be achieved for $1.0 \times 10^{18} \mathrm{~cm}^{-3} \lesssim[\mathrm{Mg}] \lessgtr 9.0 \times 10^{19} \mathrm{~cm}^{-3}$. The systematic change of free-charge carrier properties with $\mathrm{Mg}$ concentration is discussed in relation to the evolution of extended defect density and growth mode. A comparison between the structural characteristics and free electron concentrations in the films provides insights in the role of extended and point defects for the $n$-type conductivity in InN. It further allows to suggest pathways for achieving compensated InN material with relatively high electron mobility and low defect densities. The critical values of $\mathrm{Mg}$ concentration for which polarity inversion and formation of zinc-blende InN occurred are determined. Finally, the effect of $\mathrm{Mg}$ doping on the lattice parameters is established and different contributions to the strain in the films are discussed. (C) 2014 AIP Publishing LLC.
\end{abstract}

[http://dx.doi.org/10.1063/1.4871975]

\section{INTRODUCTION}

InN and related alloys have attracted much research interest due to their unique properties and potential for applications in solar cells, high speed electronics, terahertz emitters, and various light emitting devices from the infrared to the ultraviolet spectral range. ${ }^{1}$ Despite the intense investigation, controllable $n$ - and $p$-type doping in InN and In-rich alloys is still very challenging, mostly because of the peculiar electronic band structure of the material. In particular, $p$-type doping in $\mathrm{InN}$ is difficult to be either achieved or assessed. Because of the low band gap energy of $0.65 \mathrm{eV}$ and high electron affinity, the Fermi stabilization energy or so-called branch point in InN lies high in the conduction band. ${ }^{2}$ Consequently, native defects have donor character. ${ }^{3}$ Furthermore, most common unintentional impurities, such as $\mathrm{H}, \mathrm{O}$, and $\mathrm{Si}$ also act as donors. ${ }^{4,5}$ As a result InN epitaxial films are typically unintentionally $n$-type doped with relatively high free electron concentrations. State-of-the-art InN films grown by molecular beam epitaxy (MBE) have room temperature bulk electron concentrations as low as

${ }^{\text {a)} E-m a i l: ~ v a n y a @ i f m . l i u . s e ~}$
$1.5-4.0 \times 10^{17} \mathrm{~cm}^{-3}$ (Refs. 6-10) and high electron mobilities, with a record value of $3280 \mathrm{~cm}^{2} / \mathrm{V} \mathrm{s}{ }^{10}$

Theoretical calculations have predicted that $\mathrm{Mg}$ is a shallow acceptor ${ }^{5}$ while $\mathrm{C}^{5}$ and $\mathrm{Mn}^{11}$ act as deeper acceptors. Even in the case of $\mathrm{Mg}$, the ionization energy of about $0.1 \mathrm{eV}$ is relatively large and therefore only a small part of the $\mathrm{Mg}$ acceptors will be ionized at room temperature. In order for $\mathrm{Mg}$ doped $\mathrm{InN}$ ( $\mathrm{InN}: \mathrm{Mg}$ ) to manifest $p$-type conductivity it is necessary that the concentration of ionized acceptors exceeds the concentration of ionized donors. As a result, relatively low free hole concentrations may be expected even in state-of-the-art InN:Mg films with low unintentional electron doping. In addition, a strong electron accumulation occurs at the InN film surfaces ${ }^{12,13}$ with a large sheet density in the low-to-mid $10^{13} \mathrm{~cm}^{-2}$ range. ${ }^{12-17}$ Consequently, detecting potential $p$-type conductivity in the InN bulk using conventional contact-based electrical measurements is not possible, since the surface inversion layer with high electron density conceals the region with free holes. ${ }^{18}$

$\mathrm{Up}$ to date, only $\mathrm{Mg}$ has proven to successfully $p$-type dope $\mathrm{InN},{ }^{18-21}$ and free holes in InN:Mg films have been experimentally identified by electrolyte capacitance-voltage, ${ }^{18,22,23}$ thermopower, ${ }^{23-25}$ variable magnetic field electrical Hall 
effect, ${ }^{26}$ temperature-dependent electrical Hall effect, ${ }^{27}$ and infrared reflectometry ${ }^{28}$ measurements. Very recently, we have reported the application of infrared spectroscopic ellipsometry (IRSE) and optical Hall effect to evidence $p$-type conductivity in InN:Mg films and determine the free carrier parameters. ${ }^{29}$ All methods have consistently shown that $\mathrm{InN}$ doped with $\mathrm{Mg}$ concentration below $1.0 \times 10^{18} \mathrm{~cm}^{-3}$ still shows $n$-type conductivity. ${ }^{22,23,29}$ This was explained as a result of the insufficient concentration of ionized $\mathrm{Mg}$ acceptors to overcome the residual background $n$-type doping. For $\mathrm{Mg}$ concentrations in the range between $1.0 \times 10^{18} \mathrm{~cm}^{-3}$ and $2.9 \times 10^{19} \mathrm{~cm}^{-3} p$-type doped InN is achieved with free hole concentrations in the low $10^{18} \mathrm{~cm}^{-3}$ range. $^{22,23,29}$ If the $\mathrm{Mg}$ concentration is further increased, the conductivity in $\mathrm{InN}$ switches again to $n$-type possibly due to donor defects induced by the $\mathrm{Mg}$ incorporation. ${ }^{22,23,29}$ The range of $\mathrm{Mg}$ concentrations of the $p$-type window in InN may vary depending on the growth conditions which determine the microstructure and impurity/dopant incorporation in the films. ${ }^{22,23}$ Establishing the effect of Mg incorporation on the structural properties and their interrelation with free-charge carrier $(\mathrm{FCC})$ parameters is thus very important in order to better understand and optimize $p$-type doping in $\mathrm{InN}$. However, the studies of the structural properties of $\mathrm{Mg}$ doped InN films have not been exhaustive and no information on how defects affect the FCC properties exist in the literature. ${ }^{30-34}$

Previously, it was reported that the polarity of $\mathrm{InN}$ films doped with $\mathrm{Mg}$ is inverted from In to $\mathrm{N}$ when the $\mathrm{Mg}$ concentration exceeds $10^{19} \mathrm{~cm}^{-3} \cdot 30,34$ Positron annihilation studies of N-polar InN:Mg identified nitrogen vacancy clusters for $\mathrm{Mg}$ concentrations below $2 \times 10^{19} \mathrm{~cm}^{-3}$ while for $\mathrm{Mg}$ concentrations above the $p$-type window (when the conductivity is switched to $n$-type again) complexes between indium vacancy and nitrogen vacancy clusters were found. ${ }^{35}$ Recently, Choi et $_{\text {al. }}{ }^{36}$ reported on the degradation of surface morphology and onset of polarity inversion for $\mathrm{Mg}$ concentration above $7 \times 10^{19} \mathrm{~cm}^{-3}$. It has also been found that zinc-blende ( $\mathrm{ZB}) \mathrm{InN}$ is formed when $\mathrm{Mg}$ concentration exceeds $1.8 \times 10^{20} \mathrm{~cm}^{-3}$ (Ref. 34) and $2.5 \times 10^{20} \mathrm{~cm}^{-3} .31$ However, there is no systematic investigation of the effect of
$\mathrm{Mg}$ incorporation on the extended defects and growth mode in $\mathrm{Mg}$ doped $\mathrm{InN}$, and their interrelation with FCC properties. The effect of $\mathrm{Mg}$ doping on the lattice parameters of InN films is unknown.

In this work, we present a comprehensive study of the FCC and structural properties of InN films systematically doped with Mg. IRSE is used to assess the type of doping and the free electron and hole concentration, mobility, and plasmon broadening parameters. The lattice parameters, microstructure, and surface morphology are determined by high-resolution X-ray diffraction (HRXRD) and atomic force microscopy (AFM).

\section{EXPERIMENTAL AND DATA ANALYSIS}

Two sets of wurtzite (WZ) InN films with $c$-plane orientations grown by plasma-assisted MBE and doped with varying $\mathrm{Mg}$ concentrations were studied (Table I). In the first set, hereafter called set $\mathrm{A}$, seven $\mathrm{InN}$ films were grown on 4.1- $\mu \mathrm{m}$-thick metal-organic vapor phase epitaxy (MOVPE) Ga-polar $c$-plane GaN/sapphire templates. The growth temperature was $480^{\circ} \mathrm{C}$ and slightly In-rich conditions were used. ${ }^{33}$ For all samples in set A, the InN growth started with a $50 \mathrm{~nm}$ undoped layer followed by a $400 \mathrm{~nm}$ thick $\mathrm{Mg}$ doped InN layer. In the second set, hereafter called set B, eight InN films were grown on 1.7- $\mu$ m-thick MOVPE GaN on sapphire. ${ }^{23}$ Similar to the first set, before the $\mathrm{Mg}$ doped InN layer, a 60-nm-thick undoped $\mathrm{InN}$ interlayer was grown at $450^{\circ} \mathrm{C}^{23}$ The InN films of set $\mathrm{B}$ were grown using the droplet elimination by radical beam irradiation method. ${ }^{37}$ Two samples from set $\mathrm{B}$ with the same $\mathrm{Mg}$ concentration of $2.3 \times 10^{20} \mathrm{~cm}^{-3}$ were grown under different $\mathrm{In} / \mathrm{N}$ growth ratio: B7 under N-rich and B8 under slightly In-rich growth conditions (Table I). The rest of the samples from set $\mathrm{B}$ were grown at slightly In-rich conditions. The MOVPE GaN templates for the two sample sets have high crystalline quality with $\mathrm{GaN}$ (0002) rocking curve (RC) full-width at half maximum of 6 arcsec. The two sets include undoped InN reference samples and $\mathrm{Mg}$-doped $\mathrm{InN}$ films with systematically

TABLE I. FCC and structural characteristics of the InN films from set A and set B: $N$ and $\mu$ are the free-charge carrier concentration and mobility, respectively; $N_{\mathrm{scw}}$ and $N_{\mathrm{ed}}$ are the density of screw and edge type dislocations, respectively; $R M S$ is the root mean square roughness.

\begin{tabular}{|c|c|c|c|c|c|c|c|c|}
\hline Sample & {$[\mathrm{Mg}]\left(\mathrm{cm}^{-3}\right)$} & $N\left(\times 10^{17} \mathrm{~cm}^{-3}\right)$ & $\mu\left(\mathrm{cm}^{2} / \mathrm{V} \mathrm{s}\right)$ & tilt (deg) & $N_{\mathrm{scw}}\left(\times 10^{8} \mathrm{~cm}^{-2}\right)$ & twist (deg) & $N_{\mathrm{ed}}\left(\times 10^{10} \mathrm{~cm}^{-2}\right)$ & $R M S(\mathrm{~nm})$ \\
\hline A1 & $0(\mathrm{n})$ & $11.6 \pm 0.5$ & $1601 \pm 87$ & $0.15 \pm 0.02$ & $4.6 \pm 1$ & $0.65 \pm 0.06$ & $2.4 \pm 0.4$ & 1.0 \\
\hline $\mathrm{A} 2$ & $1.0 \times 10^{18}(\mathrm{p})$ & $3.3 \pm 0.1$ & $21 \pm 1$ & $0.17 \pm 0.02$ & $6.2 \pm 1$ & $0.76 \pm 0.06$ & $3.3 \pm 0.5$ & 0.9 \\
\hline A3 & $5.8 \times 10^{18}(\mathrm{p})$ & $1.6 \pm 0.1$ & $24 \pm 1$ & $0.18 \pm 0.01$ & $7.2 \pm 0.9$ & $0.66 \pm 0.04$ & $2.5 \pm 0.3$ & 1.2 \\
\hline A4 & $2.9 \times 10^{19}(\mathrm{p})$ & $3.3 \pm 0.1$ & $30 \pm 2$ & $0.17 \pm 0.01$ & $6.1 \pm 0.5$ & $0.70 \pm 0.01$ & $2.8 \pm 0.08$ & 1.3 \\
\hline A5 & $1.8 \times 10^{20}(\mathrm{n})$ & $9.20 \pm 0.04$ & $1079 \pm 40$ & $0.20 \pm 0.03$ & $8.1 \pm 2$ & $0.54 \pm 0.06$ & $1.6 \pm 0.3$ & 8.1 \\
\hline A6 & $8.0 \times 10^{20}(\mathrm{n})$ & $77.6 \pm 0.3$ & $203 \pm 4$ & $0.30 \pm 0.001$ & $19 \pm 0.2$ & $0.61 \pm 0.1$ & $2.1 \pm 0.7$ & 13.5 \\
\hline A7 & $3.9 \times 10^{21}(\mathrm{n})$ & $\ldots$ & $\ldots$ & $0.51 \pm 0.06$ & $56 \pm 10$ & $0.92 \pm 0.04$ & $4.7 \pm 0.4$ & 33.1 \\
\hline $\mathrm{B} 1$ & $0(\mathrm{n})$ & $7.66 \pm 0.02$ & $1399 \pm 60$ & $0.14 \pm 0.004$ & $4.2 \pm 0.3$ & $0.85 \pm 0.04$ & $4.0 \pm 0.3$ & 4.1 \\
\hline $\mathrm{B} 2$ & $1.0 \times 10^{18}(\mathrm{n})$ & $4.56 \pm 0.05$ & $714 \pm 74$ & $0.14 \pm 0.03$ & $4.3 \pm 2$ & $0.88 \pm 0.06$ & $4.3 \pm 0.6$ & 3.4 \\
\hline B3 & $9.0 \times 10^{18}(\mathrm{p})$ & $3.5 \pm 0.1$ & $20 \pm 1$ & $0.13 \pm 0.02$ & $3.9 \pm 1$ & $0.87 \pm 0.01$ & $4.3 \pm 0.1$ & 1.7 \\
\hline B4 & $2.2 \times 10^{19}(\mathrm{p})$ & $2.1 \pm 0.5$ & $20 \pm 2$ & $0.13 \pm 0.02$ & $3.6 \pm 1$ & $0.90 \pm 0.05$ & $4.5 \pm 0.5$ & 2.1 \\
\hline B5 & $5.6 \times 10^{19}(\mathrm{p})$ & $2.3 \pm 0.2$ & $22 \pm 1$ & $0.16 \pm 0.003$ & $5.6 \pm 0.2$ & $0.87 \pm 0.02$ & $4.3 \pm 0.2$ & 3.2 \\
\hline B6 & $9.0 \times 10^{19}(\mathrm{p})$ & $0.8 \pm 0.6$ & $23 \pm 2$ & $0.16 \pm 0.02$ & $5.5 \pm 1$ & $0.81 \pm 0.06$ & $3.7 \pm 0.5$ & 9.0 \\
\hline B7 N-rich & $2.3 \times 10^{20}(\mathrm{n})$ & $0.14 \pm 0.02$ & $766 \pm 26$ & $0.13 \pm 0.01$ & $3.6 \pm 0.5$ & $0.62 \pm 0.02$ & $2.2 \pm 0.1$ & 8.9 \\
\hline B8 In-rich & $2.3 \times 10^{20}(\mathrm{n})$ & $0.047 \pm 0.004$ & $608 \pm 30$ & $0.17 \pm 0.01$ & $6.3 \pm 0.8$ & $0.88 \pm 0.05$ & $4.3 \pm 0.5$ & 10.7 \\
\hline
\end{tabular}


increased $\mathrm{Mg}$ concentration ranging from $1.0 \times 10^{18} \mathrm{~cm}^{-3}$ to $3.9 \times 10^{21} \mathrm{~cm}^{-3}$ for set $\mathrm{A}$ and from $1.0 \times 10^{18} \mathrm{~cm}^{-3}$ to $2.3 \times 10^{20} \mathrm{~cm}^{-3}$ for set B (see Table I). The Mg concentrations in the samples from both sets were estimated by secondary ion mass spectrometry (see Table I). All samples from the two sets were grown with intended In-polarity. Both electrolyte capacitance voltage (ECV) measurements and IRSE demonstrated that $p$-type conductivity in the samples from set $\mathrm{A}$ was achieved for $\mathrm{Mg}$ concentrations between $1.0 \times 10^{18} \mathrm{~cm}^{-3}$ and $2.9 \times 10^{19} \mathrm{~cm}^{-3} \cdot{ }^{29,33}$ The presence of free holes in samples B3, B4, and B5 was proved by negatively shifted ECV and positive Seebeck coefficients in thermopower measurements. ${ }^{23}$

IRSE was performed at multiple angles of incidence using a variable angle J. A. Woollam Co. ellipsometer. Ellipsometry measures the change in polarization state of light upon reflection of a sample, where the measured standard ellipsometric parameters $\Psi$ and $\Delta$ are defined the ratio $\rho^{38}$

$$
\rho=\frac{R_{\mathrm{p}}}{R_{\mathrm{s}}}=\tan \Psi \exp (i \Delta) .
$$

Spectroscopic ellipsometry is an indirect method and requires a detailed model analysis in order to extract relevant physical parameters. In order to reduce parameter correlation, the IRSE data obtained at multiple angles of incidence were analyzed simultaneously for all samples by using a four-layer-stack model: sapphire substrate/GaN template layer/InN undoped buffer layer/InN layer. Dielectric function model calculations are then applied to match the experimental spectra and extract information of the dielectric function of interest. The IRSE dielectric functions of sapphire were previously determined and taken without any changes in the current work. ${ }^{39}$ The model dielectric functions of $\mathrm{GaN}$ and $\mathrm{InN}$ included contributions from lattice vibrations (phonons) and FCCs. ${ }^{40,41}$ The uncoupled phonon mode parameters and the high-frequency limit of the dielectric function of $\mathrm{GaN}$ and $\mathrm{InN}$ are taken from our previous works. ${ }^{40,42,43}$ The FCC contribution with consideration of longitudinal optical phonon plasmon coupling (LPP) was described by applying the Kukharskii model $^{29,44}$

$$
\varepsilon_{\|(\perp)}(\omega)=\varepsilon_{\infty, \|(\perp)} \frac{\left(\omega^{2}+i \gamma_{\mathrm{LPP}^{-}, \|(\perp)} \omega-\omega_{\mathrm{LPP}^{-}, \|(\perp)}^{2}\right)\left(\omega^{2}+i \gamma_{\mathrm{LPP}^{+}, \|(\perp)} \omega-\omega_{\mathrm{LPP}^{+}, \|(\perp)}^{2}\right)}{\omega\left(\omega+i \gamma_{\mathrm{p}, \|(\perp)}\right)\left(\omega^{2}+i \gamma_{\mathrm{TO}, \|(\perp)} \omega-\omega_{\mathrm{TO}, \|(\perp)}^{2}\right)}
$$

where $\omega_{\mathrm{LPP}^{-/+}, \|(\perp)}$ are the frequencies of the LO-phonon-plasmon branches $\mathrm{LPP}^{-} / \mathrm{LPP}^{+}$for directions parallel $(\|)$and perpendicular $(\perp)$ to the $\mathrm{c}$-axis

$$
\omega_{\mathrm{LPP}^{-/+}, \|(\perp)}=\sqrt{\frac{1}{2}\left[\omega_{\mathrm{p}}^{2}+\omega_{\mathrm{LO}, \|(\perp)}^{2} \pm \sqrt{\left(\omega_{\mathrm{p}}^{2}+\omega_{\mathrm{LO}, \|(\perp)}^{2}\right)^{2}}-4 \omega_{\mathrm{p}}^{2} \omega_{\mathrm{TO}, \|(\perp)}^{2}\right]},
$$

and $\gamma_{\mathrm{LPP}^{-/+}}$is the respective isotropically averaged LPP broadening parameter. $\gamma_{\mathrm{p}}$ is the plasma broadening parameter which is connected to the effective mass $m^{*}$ and the optical mobility $\mu$ by $\gamma_{\mathrm{p}}=q / m^{*} \mu$, with $|q|=e$ being the elementary charge. A regression analysis (Levenberg-Marquardt algorithm) is performed, where the model parameters are varied until calculated and experimental data match as close as possible. ${ }^{38}$ This is done by minimizing the mean square error $\left(\chi^{2}\right)$ function which is weighed to estimate experimental errors $(\sigma)$. The FCC parameters in the main InN layer, the InN undoped buffer, and $\mathrm{GaN}$ are allowed to vary during the IRSE regression analysis. The contributions of the InN undoped buffer layer and GaN template were considered the same for all samples of a particular set. The thickness of the layers were taken from the fit of the ellipsometry data in the ultraviolet region, which provide much better sensitivity to the individual thicknesses. Details about the spectroscopic ellipsometry analysis and modeling for set A, applied here for set B as well, can be found in Ref. 29.

AFM measurements were performed on Veeco Instrument Inc in tapping mode. XRD RC, 2 $\theta-\omega$ scans, reciprocal space map (RSM), and pole figure (PF) measurements were performed using monochromated $\mathrm{Cu} K_{\alpha 1}$ radiation on an Empyrean diffractometer from PANalytical. The InN lattice parameters were determined from the symmetric (0002), (0004), and (0006) for the $c$-lattice parameter, and

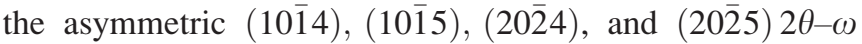
HRXRD spectra for the $a$-lattice parameter following the method described in Ref. 45. PFs were measured around the $\mathrm{ZB}$ InN (200) plane and the ZB volume fraction was estimated from the ratio of the integral intensity of the $\mathrm{ZB}$ InN (331), and WZ IN (1015) RCs, following the method described in Ref. 46. RSMs around the WZ InN symmetric (0004) and asymmetric $(10 \overline{15})$ reciprocal lattice points are measured for all InN films. The densities of screw $\left(N_{\mathrm{scw}}\right)$ and edge $\left(N_{\text {ed }}\right)$ type dislocations in the InN films were estimated from the tilt and $t w i s t$, respectively, ${ }^{47}$

$$
\begin{aligned}
N_{\text {scw }} & =\frac{t i l t^{2}}{4.35 c^{2}}, \\
N_{\text {ed }} & =\frac{t w i s t^{2}}{4.35 a^{2}},
\end{aligned}
$$

where $a$ and $c$ are the measured lattice parameters. The mosaic tilts in the InN films were obtained from the Williamson-Hall plots of the symmetric WZ InN (0002), (0004), and (0006) diffraction peaks. ${ }^{47}$ The mosaic twist was estimated using the method proposed by Srikant et al. ${ }^{48}$ 
and using the RC FWHMs of WZ InN (0002),

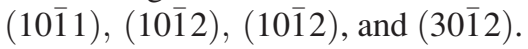

\section{RESULTS AND DISCUSSION}

\section{A. Free-charge carrier properties}

Figure 1 shows the experimental and best-match calculated IRSE $\Psi$ spectra for the samples of set B. The analysis of the IRSE spectra of set A can be found in Ref. 29. The lineshape analysis for all films from sets A and B render the carrier type, concentration, mobility and phonon-plasmon broadening parameters in the InN layer (Table I), InN buffer layer, and $\mathrm{GaN}$ template. In order to extract the carrier concentration and mobility, a value for the effective mass must be assumed. The dependence of the electron effective mass on carrier concentration reported in Ref. 49 was used for the InN $n$-type films, while in the case of free holes a constant hole effective mass of $0.42 m_{0}$ in $\mathrm{InN}^{25}$ was assumed. A value of the electron effective mass in GaN of $0.22 m_{0}$ was taken. ${ }^{40}$ The free electron concentrations in the GaN template and 50-nm-thick undoped InN buffer layer in the samples from set $\mathrm{B}$ were found to be $1.6 \times 10^{17} \mathrm{~cm}^{-3}$ and $1.2 \times 10^{19} \mathrm{~cm}^{-3}$, respectively. The FCC parameters of the InN films are listed in Table I and presented in Figs. 2 and 3. The results on the FCC properties of the InN films from set A, as obtained in Ref. 29, are included here for comparison and for further analysis in relation to the structural properties of the InN films.

We found a systematic change of the FCC concentration with increasing $\mathrm{Mg}$ concentration in the $\mathrm{InN}$ films from set $\mathrm{B}$

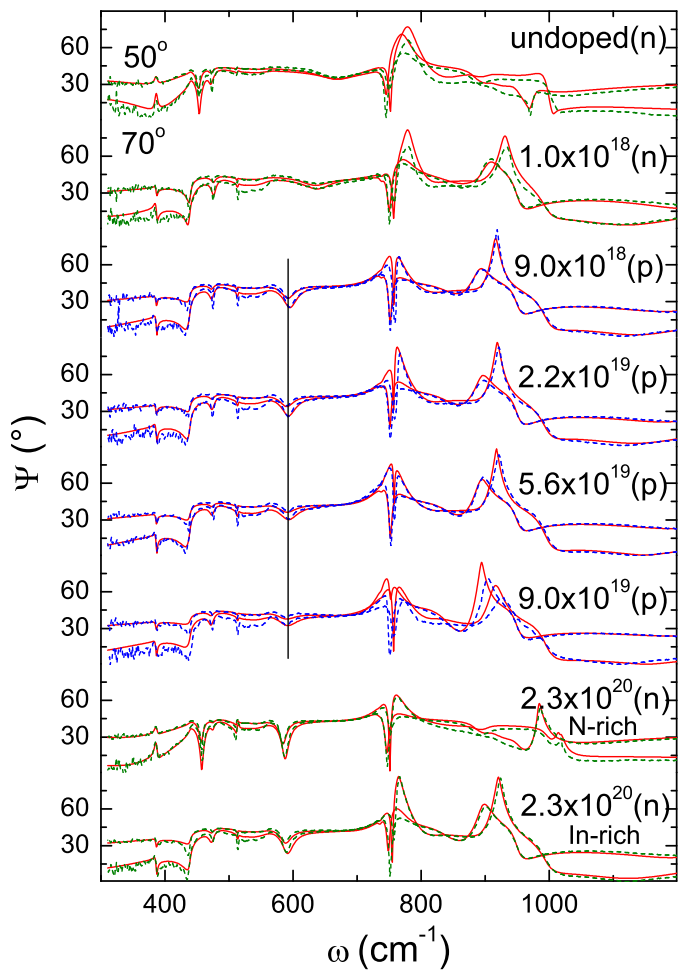

FIG. 1. Experimental (dashed lines) and best-matching model calculated IRSE $\Psi$ spectra (solid lines) at $50^{\circ}$ and $70^{\circ}$ angles of incidence for the samples of set $\mathrm{B}$. The $\mathrm{Mg}$ doping concentrations and the conductivity type is indicated above the respective spectra.
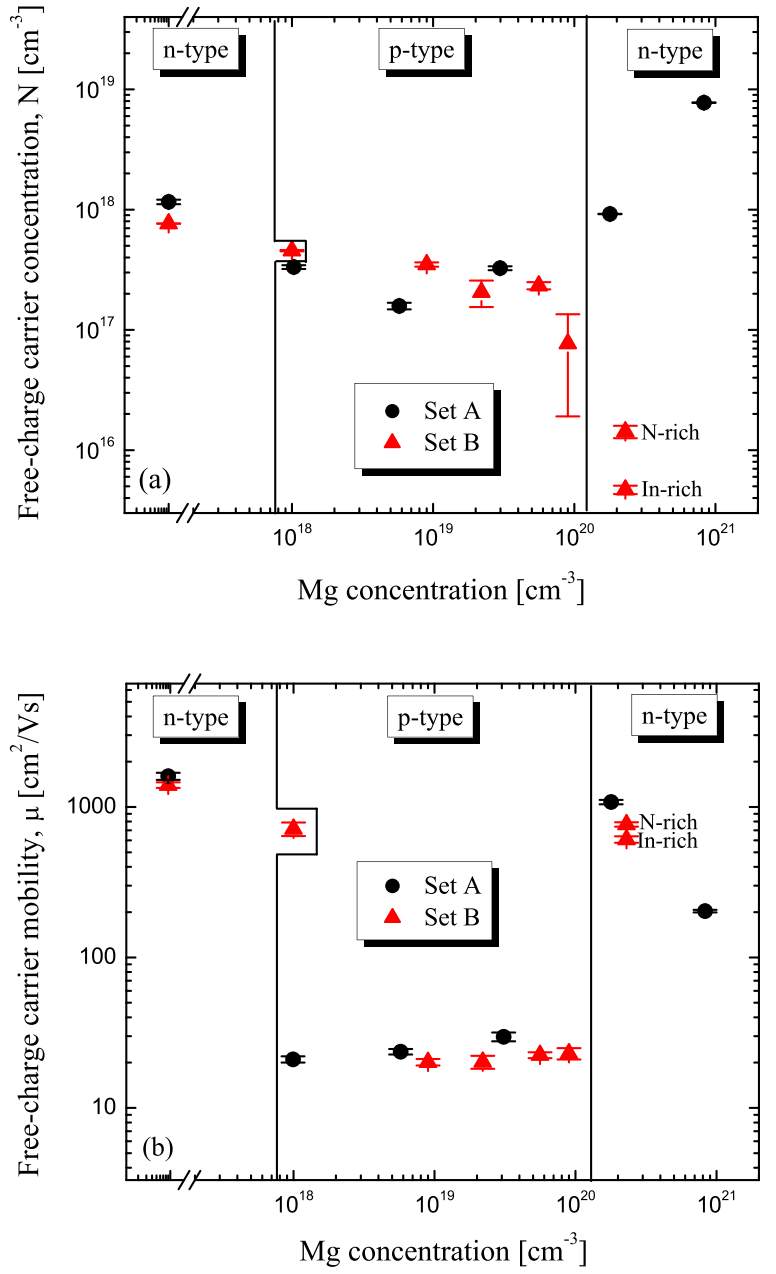

FIG. 2. Best-match calculated free-charge carrier concentration $N$ (a) and mobility $\mu$ (b) as determined from the IRSE data analysis.

similar to the results for set A. ${ }^{29}$ For the undoped sample (B1) and the lightly doped sample B2 with $[\mathrm{Mg}]=1.0 \times 10^{18} \mathrm{~cm}^{-3}$ InN shows $n$-type conductivity. For $\mathrm{Mg}$ concentrations in the range of $9.0 \times 10^{18} \mathrm{~cm}^{-3}-9.0 \times 10^{19} \mathrm{~cm}^{-3}$, the number of ionized acceptors exceeds the number of background donors, and the InN films become $p$-type conductive. This is manifested by the appearance of a dip in the infrared spectra, which is slightly above the uncoupled $\mathrm{A}_{1}$-LO mode of $\mathrm{InN}$ at around $600 \mathrm{~cm}^{-1}$ (see vertical line in Fig. 1). The dip was previously observed in the IRSE spectra of the $p$-type InN films from set A and it was related to a loss in reflectivity of $p$-polarized light as a consequence of reduced LO phonon plasmon coupling to free holes. ${ }^{29}$ This is also accompanied by a sudden increase of phonon-plasmon broadening, $\gamma_{\mathrm{LPP}^{-}}$, for the free holes [see Fig. 3(b)]. The presence of free holes in samples B3, B4, and B5 was also inferred by negatively shifted ECV and positive Seebeck coefficients in thermopower measurements. ${ }^{23}$ Sample B6 with $\mathrm{Mg}$ concentration of $9.0 \times 10^{19} \mathrm{~cm}^{-3}$ was identified as $p$-type from our IRSE analysis, but as $n$-type material by ECV and thermopower measurements. ${ }^{23}$ This discrepancy might be due to the influence of the $n$-type buffer layer on the electrical measurements. The hole mobility values in set $\mathrm{B}$ range from $21 \mathrm{~cm}^{2} / \mathrm{V} \mathrm{s}$ to $23 \mathrm{~cm}^{2} / \mathrm{V} \mathrm{s}$ in agreement with our previous results for the samples from set $\mathrm{A}^{29}$ and with the average experimental values of $23 \mathrm{~cm}^{2} / \mathrm{V}$ s from Ref. $32,26 \mathrm{~cm}^{2} / \mathrm{V} \mathrm{s}$ 

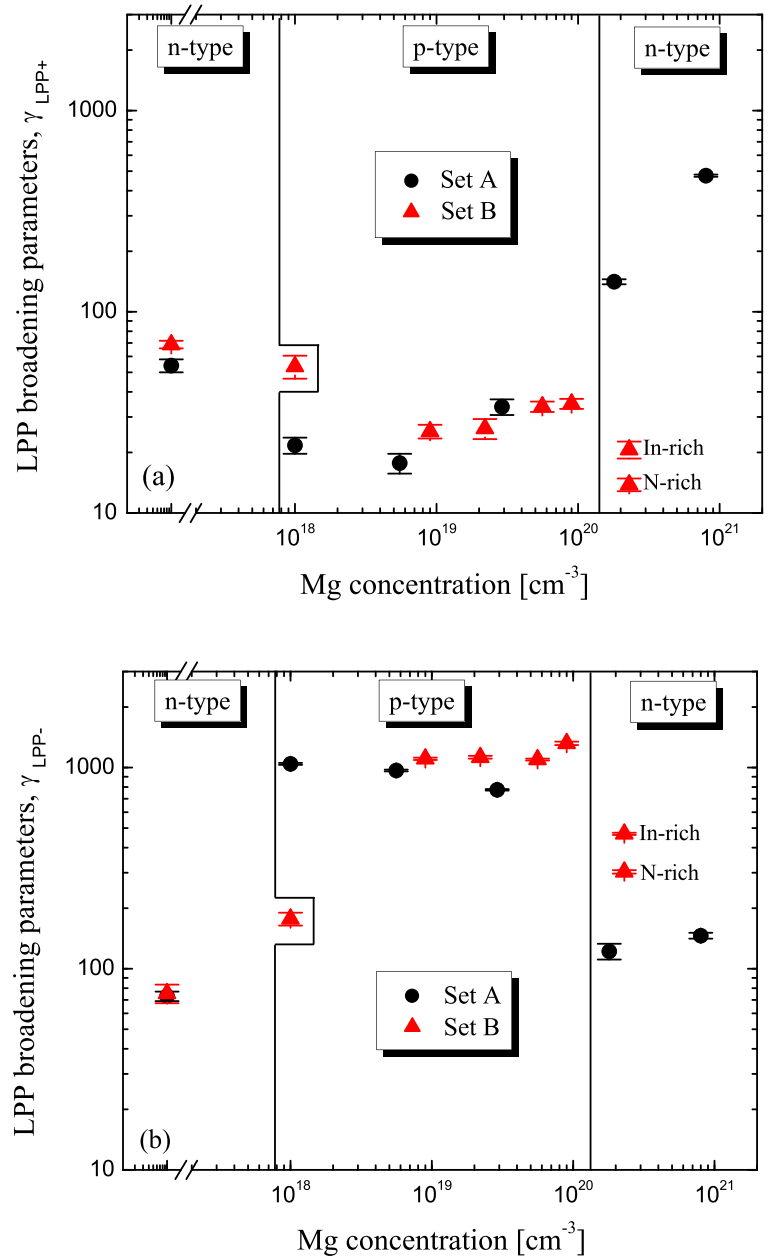

FIG. 3. Best-match calculated LPP broadening parameters: $\gamma_{\mathrm{LP}+}$ (a) and $\gamma_{\text {LPP- }}($ b) as obtained from the IRSE data analysis.

from Ref. 50, $19 \mathrm{~cm}^{2} / \mathrm{V} \mathrm{s}$ from Ref. 25, and the theoretical values of $20-70 \mathrm{~cm}^{2} / \mathrm{V}$ s from Ref. 51 .

When the $\mathrm{Mg}$ concentration is increased to $2.3 \times 10^{20} \mathrm{~cm}^{-3}$ the conductivity type is again switched to $n$ for samples B7 and B8 (Table I, Fig. 2). It is seen from Fig. 1 that the dip at around $600 \mathrm{~cm}^{-1}$ still occurs in the IRSE spectra of B7 and B8. However, noticeably smaller $\mathrm{LPP}^{-}$broadening parameters are determined for these samples [Fig. 3(b)]. A smaller $\gamma_{\mathrm{LPP}^{-}}$is related to a smaller effective mass and a higher carrier mobility and clearly indicates $n$-type behavior. We note that the attempt to model the IRSE spectra of $\mathrm{B} 7$ and $\mathrm{B} 8$ as $p$-type (assuming effective hole instead of effective electron mass) resulted in unreasonably high mobility parameters for free holes. On the other hand, modeling the spectra with free electron contribution resulted in mobility parameters of $766 \mathrm{~cm}^{2} / \mathrm{V} \mathrm{s}$ and $608 \mathrm{~cm}^{2} / \mathrm{V} \mathrm{s}$ for $\mathrm{B} 7$ and $\mathrm{B} 8$, respectively, which are well within the typical values for $n$-type conductive InN films [Fig. 2(b)].

The determined FCC parameters for the samples from set $\mathrm{B}$ are in excellent agreement with the previously reported results for set A (see Table I). However, the $p$-type window of $\mathrm{Mg}$ concentrations slightly differ between the two sets. The different conductivity behavior in samples A2 and B2 with the same $\mathrm{Mg}$ doping may be due to different growth conditions and will be further addressed when discussing the defects in the films.

\section{B. Surface morphology and growth mode}

Figure 4 shows AFM images of selected samples from sets $\mathrm{A}$ and $\mathrm{B}$, representative for the surface morphology observed for the specific ranges of $\mathrm{Mg}$ doping concentrations. The values of the root mean square (RMS) roughness of all films, estimated from the $10 \times 10 \mu \mathrm{m}^{2}$ micrographs, are plotted as a function of $\mathrm{Mg}$ concentration in Fig. 5 and listed in Table I.

For $\mathrm{Mg}$ concentration below $5.6 \times 10^{19} \mathrm{~cm}^{-3}$ (samples A1-A4 and B1-B5), the InN films exhibit smooth surfaces with RMS of $1.0 \mathrm{~nm}$ to $1.2 \mathrm{~nm}$ and a spiral hillock rich morphology characteristic for dislocation pinned step-flow growth [see Figs. 4(a) and 4(b)]. ${ }^{52,53}$ This morphology is typical for high quality In-polar InN films. ${ }^{30,53-55}$ However, for $\mathrm{Mg}$ concentration of $9.0 \times 10^{19} \mathrm{~cm}^{-3}$ or higher (samples A5-A7, B6-B8), the surface morphology drastically changes, revealing 3D columnar-like growth [see Figs. 4(c) and 4(d)] that can be typically observed in N-polar InN films. ${ }^{56}$ The change of morphology is accompanied with the formation of large structures with oval shape and a noticeable increase of the RMS roughness above $10 \mathrm{~nm}$ (Fig. 5). These structures are few and have relatively large size for the films with $\mathrm{Mg}$
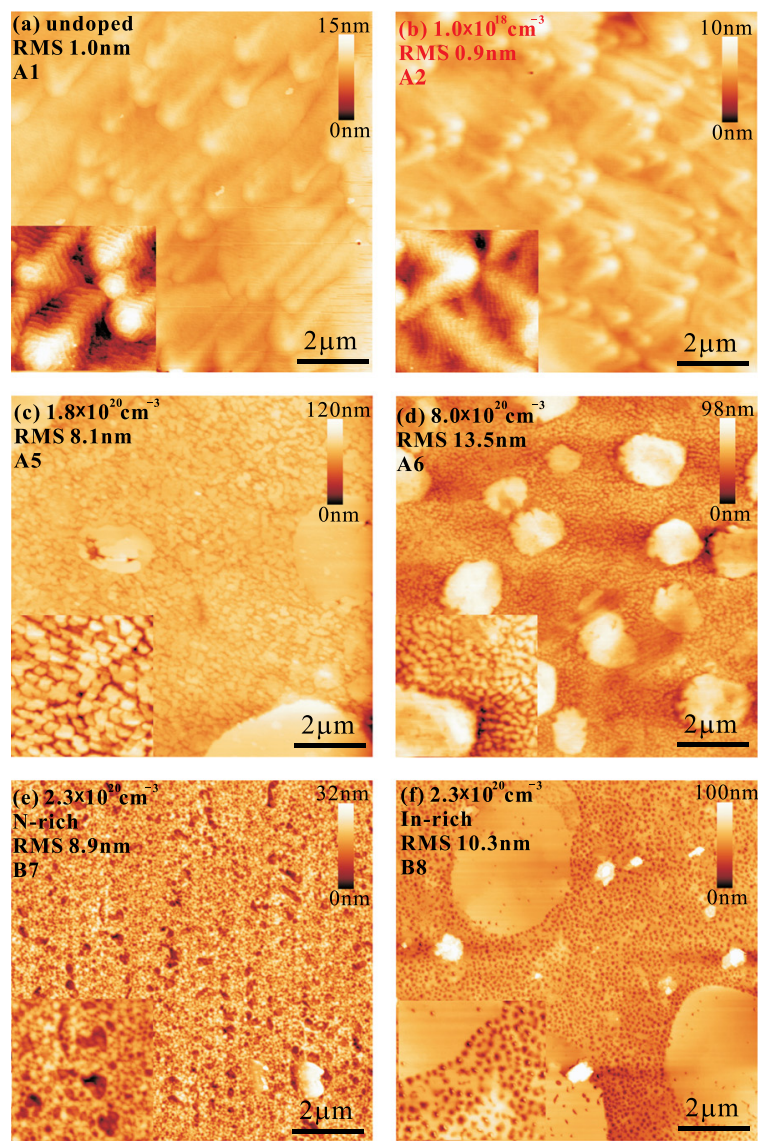

FIG. 4. $10 \times 10 \mu \mathrm{m}^{2}$ AFM images of (a) the undoped (A1), (b-d) Mg-doped InN samples from set $\mathrm{A}$ with different $\mathrm{Mg}$ concentrations (A2, A5, and $\mathrm{A} 6$ ), (e) sample B7 with $[\mathrm{Mg}]=2.3 \times 10^{20} \mathrm{~cm}^{-3}$ and grown under N-rich conditions, and (f) sample B8 with $[\mathrm{Mg}]=2.3 \times 10^{20} \mathrm{~cm}^{-3}$ and grown under In-rich conditions. The insets in (a)-(f) show $2 \times 2 \mu \mathrm{m}^{2}$ magnified AFM images. 


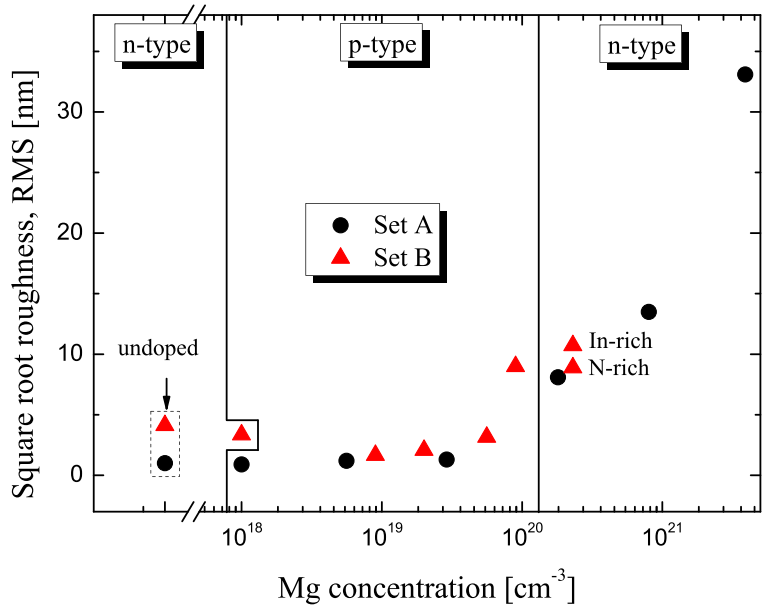

FIG. 5. Measured RMS roughness of the films from the two sets A and B as function of $\mathrm{Mg}$ concentrations.

concentrations of $(0.9-1.8) \times 10^{20} \mathrm{~cm}^{-3}$ [see Fig. 4(c)]. With increasing $\mathrm{Mg}$ concentration, the density of these structures increases and their size decreases [see Fig. 4(d)]. Note that all $p$-type InN films, except B6, exhibit smooth and step flow growth surface morphology indicative of In-polar material. This result agrees well with the range of $\mathrm{Mg}$ concentrations between $1 \times 10^{19} \mathrm{~cm}^{-3}$ (Refs. 30 and 34) and $7 \times 10^{19} \mathrm{~cm}^{-3},{ }^{36}$ for which the onset of polarity inversion in In-polar InN films was previously reported.

In-polar films are typically grown at much lower temperatures compared to their N-polar counterparts due to the lower decomposition temperature of In-polar $\operatorname{InN} .^{31}$ Furthermore, the optimum growth regime for fabricating high-quality $\mathrm{InN}$ is at the border between In-droplet and Nrich regimes at slightly In-rich conditions. ${ }^{55}$ In contrast, the optimal growth regime for $\mathrm{N}$-polar material is at significantly higher temperatures (typically above $540^{\circ} \mathrm{C}$ ), lower III/V ratios and at the border between the In-droplet and Inadlayer regimes. ${ }^{57}$ Therefore, once the polarity inversion takes place the same point in the In-polar InN growth diagram now corresponds to highly In-rich region for the
$\mathrm{N}$-polar growth diagram, which is very far from the optimal growth conditions of N-polar InN. This can explain the deterioration of surface morphology observed for the samples from both sets with $[\mathrm{Mg}] \geq 9.0 \times 10^{19} \mathrm{~cm}^{-3}$. At such growth conditions, it is plausible to suggest that the formation of In-droplets will be enhanced. Therefore, the large oval structures that begin to appear with the on-set of polarity inversion may be associated with In-droplets or areas with In-polarity. In this respect, it is very instructive to compare the two samples from set B with the same $\mathrm{Mg}$ concentration of $2.3 \times 10^{20} \mathrm{~cm}^{-3}$ but grown under different III/V growth ratios. Representative AFM micrographs of these samples are shown in Figs. 4(e) and 4(f). It is seen that sample B8 grown under In-rich conditions [Fig. 4(f)] shows the oval structures on the surface while no such features can be detected on the surface of sample B7 grown under N-rich conditions [Fig. 4(e)]. These results support our suggestion that the large oval structures observed at the surfaces of the InN films with high $\mathrm{Mg}$ concentration could be associated with In-droplets. This is further confirmed by additional compositional analysis and $\mathrm{HCl}$ etching.

\section{Microstructure}

The RSMs around the WZ InN (0004) reciprocal lattice point taken from the samples of set A are shown as examples in Fig. 6. Similar results are obtained for the samples from set B. All RSMs show elliptical shape typically observed for group-III nitride heteroepitaxial layers due to the limited coherence lengths of the mosaic blocks. ${ }^{58}$ It is also seen that the RSMs are asymmetrically elongated in the $q_{z}$-direction towards smaller scattering vectors (larger $c$-lattice parameters). Similar elongation is observed for the undoped and $p$-type conductive InN films [Figs. 6(a)-6(d)] indicating that the elongation is not related to $\mathrm{Mg}$ doping. It is most probably due to strain relaxation along the InN films' thicknesses and the presence of InN buffer layer with a larger $c$-lattice parameter. ${ }^{59}$ As a result of lattice and thermal expansion coefficient mismatches, a compressive in-plan strain and
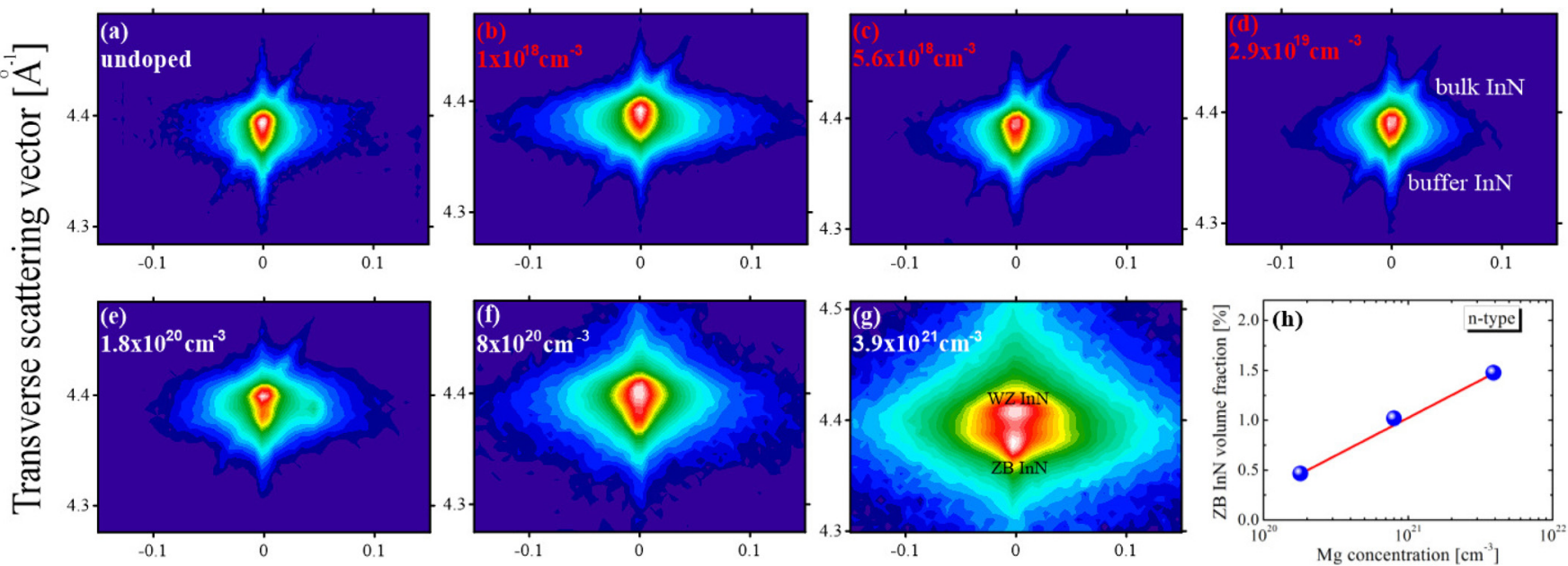

Lateral scattering vector $\left[\AA^{-1}\right]$

FIG. 6. Symmetric (0004) reciprocal space maps (RSMs) for the samples from set A (a-g) and (h) ZB InN volume fraction as function of Mg concentration. 
tensile out-of-plane strain is generated in $\mathrm{InN}$ films on $\mathrm{GaN} / \mathrm{sapphire}$. Thus, larger $c$-lattice parameters would be expected in the biaxially strained $\mathrm{InN}$ films as suggested above. It should be also noted that the RSM FWHMs along both $q_{x}$ and $q_{z}$ directions are nearly the same with changing [Mg] up to $1.8 \times 10^{20} \mathrm{~cm}^{-3}$ for sample set A [Figs. 6(a)-6(e)] and $2.3 \times 10^{20} \mathrm{~cm}^{-3}$ for the samples from set $\mathrm{B}$, respectively.

Significantly broader RSMs along the $q_{x}$ and $q_{z}$ directions are observed for $[\mathrm{Mg}] \geq 8 \times 10^{20} \mathrm{~cm}^{-3}$ [Figs. $6(\mathrm{f})$ and $\left.6(\mathrm{~g})\right]$. For sample A7 with the highest $[\mathrm{Mg}]=3.9 \times 10^{21} \mathrm{~cm}^{-3}$, two separate peaks are well resolved in the RSM [Fig. 6(g)]. In addition to the main WZ InN (0004), an extra peak appears at smaller $q_{z}$ and which can be associated with diffraction from $\mathrm{ZB} \mathrm{InN} \mathrm{(222).} \mathrm{In} \mathrm{order} \mathrm{to} \mathrm{confirm} \mathrm{this} \mathrm{assignment,} \mathrm{we} \mathrm{per-}$ formed PF measurements of ZB InN (200) peak at $2 \theta=36^{\circ}$. Note that no WZ-InN peak exists around these scattering angles which allows for unambiguous identification of ZB InN. Figure 7 shows the stereographic projection of the PF for sample A7, revealing six peaks rotated with respect to each other by $60^{\circ}$ at an angle of inclination $\Psi \sim 57^{\circ}$. This is consistent with $\mathrm{ZB}$ InN growing with the [111] direction parallel to the surface normal as inferred from the RSM in Fig. 6(g). The presence of ZB InN was also detected in the InN films $\mathrm{A} 5$ and $\mathrm{A} 6$ with $[\mathrm{Mg}] \geq 1.8 \times 10^{20} \mathrm{~cm}^{-3}$, which is in excellent agreement with the $[\mathrm{Mg}]=1.8 \times 10^{20} \mathrm{~cm}^{-3}$, previously estimated from transmission electron microscopy to be the upper limit for the on-set of ZB InN formation in similar samples (set A). ${ }^{34}$ Obviously, the value of this critical $[\mathrm{Mg}]$ should be affected by growth conditions. Indeed, no $\mathrm{ZB}$ InN could be detected in the samples from set $B$ even at $[\mathrm{Mg}]=2.3 \times 10^{20} \mathrm{~cm}^{-3}$. This result is in agreement with previous works on similar samples (set B) for which the formation of $\mathrm{ZB} \mathrm{InN} \mathrm{was} \mathrm{reported} \mathrm{to} \mathrm{occur} \mathrm{at}$ $[\mathrm{Mg}]=6.3 \times 10^{20} \mathrm{~cm}^{-3} \cdot{ }^{31}$ We estimated the volume fraction of $\mathrm{ZB} \mathrm{InN} \mathrm{in} \mathrm{the} \mathrm{samples} \mathrm{from} \mathrm{set} \mathrm{A} \mathrm{to} \mathrm{be} 0.5 \%, 1.09 \%$, and $1.48 \%$, for A5, A6, and A7, respectively [see Fig. 6(h)]. The lower volume fraction of $\mathrm{ZB}$ InN in $\mathrm{A} 5$ and A6 provides a possible explanation why a separate ZB InN (222) peak cannot be unambiguously resolved in the RSMs of these samples [Figs. 6(e) and 6(f)]. The less pronounced diffraction due to $\mathrm{ZB} \mathrm{InN}$

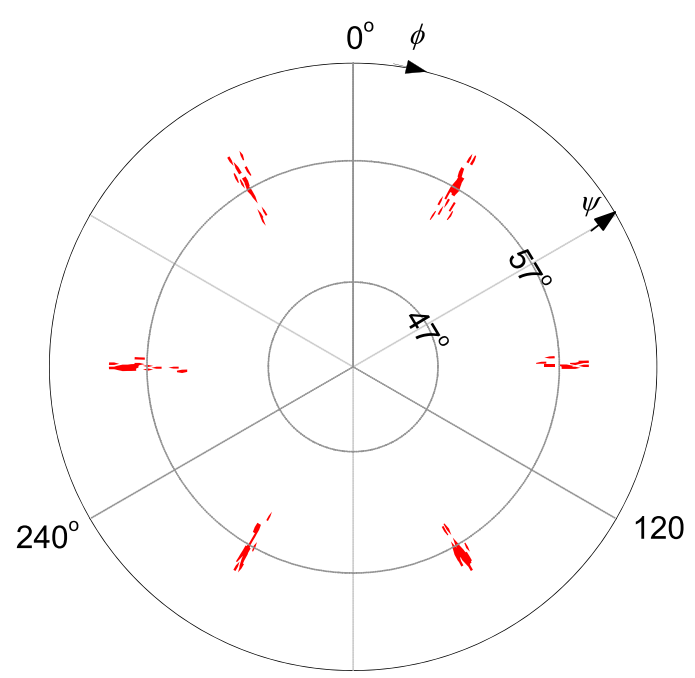

FIG. 7. Pole figure in stereographic projection of the ZB InN (200) peak for sample A7.
(222) peak in the RSMs of A5 and A6 become submerged by the $\mathrm{InN}$ strain relaxation giving rise to the elongation in the $q_{z}$ direction as discussed above [Figs. 6(e) and 6(f)]. The results in Fig. 6(h) indicate a distinct linear correlation between the $\mathrm{Mg}$ concentration and the $\mathrm{ZB} \mathrm{InN} \mathrm{volume} \mathrm{fraction} \mathrm{for}$ $[\mathrm{Mg}]=\geq 1.8 \times 10^{20} \mathrm{~cm}^{-3} . \mathrm{ZB} \mathrm{InN(111)} \mathrm{and} \mathrm{WZ} \mathrm{InN} \mathrm{(0001)}$ differ only by their stacking sequence and therefore inclusion of $\mathrm{ZB} \mathrm{InN} \mathrm{leads} \mathrm{to} \mathrm{the} \mathrm{presence} \mathrm{of} \mathrm{stacking} \mathrm{faults} \mathrm{(SFs)} \mathrm{in} \mathrm{WZ}$ InN. ${ }^{60}$ We therefore speculate that $\mathrm{Mg}$ incorporation leads to the generation of stacking faults and after a critical concentration of $\mathrm{Mg}\left([\mathrm{Mg}]=1.8 \times 10^{20} \mathrm{~cm}^{-3}\right.$ for the samples from set A), the density of SFs is sufficiently high that $\mathrm{ZB} \mathrm{InN} \mathrm{inclu-}$ sions start to form.

We also estimated the density of screw, $N_{\text {scw }}$, and edge, $N_{\text {ed }}$, type dislocations in the films from the respective tilts and twists. All results are listed in Table I, $N_{\text {scw }}$ and $N_{\text {ed }}$ are plotted as a function of $\mathrm{Mg}$ concentration in Fig. 8. $N_{\text {ed }}$ are the predominant type of dislocations in the Mg-doped $\mathrm{InN}$ films similar to undoped $\mathrm{InN}^{61,62}$ and other group-III nitride epitaxial films. It is seen from Fig. 8 that $N_{\text {scw }}$ and $N_{\text {ed }}$ do not change significantly for the range of $[\mathrm{Mg}]$ covering the $p$-type window and the densities of dislocations remain very similar to the respective values found in the undoped films. This observation is consistent for the samples from both sets, which show very similar densities of dislocations in this range of $\mathrm{Mg}$ concentrations.

For the heavily doped InN films A5-A7, a slight increase in density of edge type dislocations can be seen (see Fig. 8 and Table I). On the other hand, the density of screw type dislocations increases almost an order of magnitude with increasing $[\mathrm{Mg}]$ (see Fig. 8 and Table I). Note that the free electron concentration in these samples also increases by about an order of magnitude and the carrier mobility drops significantly (see Fig. 2 and Table I). It has been argued in the literature that either dislocations ${ }^{63,64}$ or $\mathrm{H}$ and $\mathrm{O}$ impurities, ${ }^{16,17,65}$ are most likely the sources of the unintentional $n$-type conductivity in as-grown InN. However, usually the edge type dislocations have been considered when no correlation between free electron concentration and the dislocation densities is reported. ${ }^{16,17,65}$ Our results indicate that screw dislocations, although two-orders of

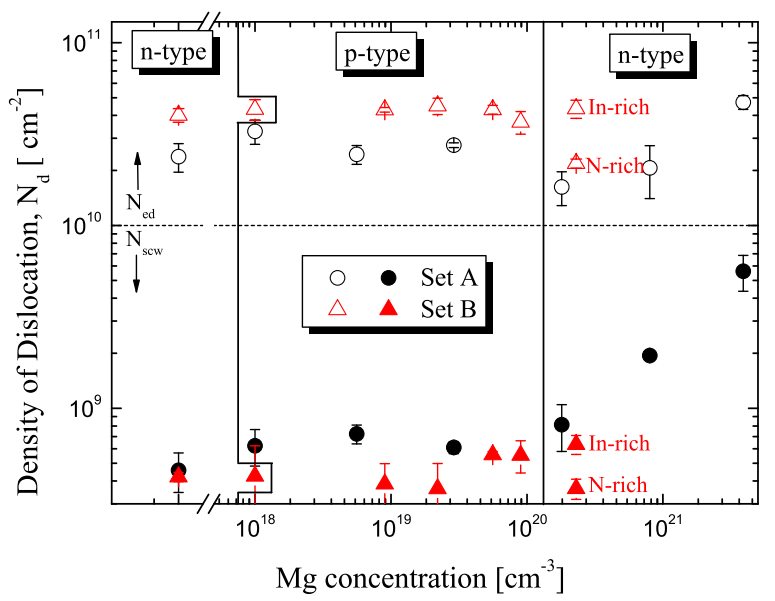

FIG. 8. Density of screw $\left(N_{\text {scw }}\right)$ and edge $\left(N_{\text {ed }}\right)$ type dislocations in the InN films from the two sets as function of $\mathrm{Mg}$ concentration. 
magnitude lower compared to edge dislocations, may play a role for the $n$-type conductivity, in particular for this range of free-electron concentrations. However, the $\mathrm{ZB} \mathrm{InN}$ fraction also scale linearly with increasing $[\mathrm{Mg}]$ in the heavily doped samples [see Fig. 6(h)]. Therefore, other defects, such as stacking faults and/or $\mathrm{ZB} \mathrm{InN} \mathrm{inclusions} \mathrm{might} \mathrm{have} \mathrm{an} \mathrm{effect}$ on the observed increase of the free electron concentration. It should also be mentioned that the undoped $\mathrm{InN}$ from set $\mathrm{B}$ (B1) shows slightly lower free electron concentration compared to the undoped film from set A (A1) while their $N_{\text {scw }}$ are very similar. Moreover, $N_{\text {ed }}$ is slightly higher in B1 compared to A1 (see Table I and Fig. 8) and the Mg concentration, at which the conductivity switches from $n$ to $p$ is higher in set $\mathrm{B}$. These results indicate a very complex interrelation between extended defects and conductivity and suggest that additional factors such as point defects and impurities are playing role for the unintentional doping as well, in particular for the range of low free electron concentrations below $10^{18} \mathrm{~cm}^{-3}$. In this respect it is also interesting to consider the samples B7 and B8 which represent highly compensated material with very low electron concentration in the $10^{16} \mathrm{~cm}^{-3}$ range [see Table I and Fig. 2(a)]. $N_{\text {ed }}$ and $N_{\text {scw }}$ for sample B7, grown under $\mathrm{N}$-rich condition, are lower than the corresponding values for sample B8, grown under In-rich condition (Fig. 8) which is consistent with the polarity inversion scenario discussed above. On the other hand, the free electron concentration in the InN films B7 and B8 anticorrelates with the dislocation density and suggests another origin of the $n$-type conductivity in this case. Indeed in our previous works we found large $\mathrm{H}$ concentrations in $\mathrm{InN}$ films grown by MBE under different growth conditions and in different laboratories. ${ }^{17,60}$ Very recent works indicate that $\mathrm{O}$ may also play an important role for the conductivity in InN:Mg films. ${ }^{66}$

The observed increase of the screw dislocation density and the substantial increase of the symmetric and asymmetric RSM broadening [see Figs. 6(f) and 6(g)] for the heavily doped InN films (see Fig. 8) can be correlated with the increase of the surface roughness (Fig. 5). This is consistent with the suggested polarity inversion scenario. The growth conditions are selected for In-polar InN and thus far from the optimal growth temperature above $540{ }^{\circ} \mathrm{C}$ for $\mathrm{N}$-polar material. Consequently, the structural quality of the InN films is lower once the polarity inversion takes place and further deteriorates with increasing $[\mathrm{Mg}]$. Further support for our reasoning comes from the comparison of the two $\mathrm{InN}$ films grown with the same $\mathrm{Mg}$ concentration of $2.3 \times 10^{20} \mathrm{~cm}^{-3}$ (above the critical value for polarity inversion, about $9 \times 10^{19} \mathrm{~cm}^{-3}$ ) under different growth conditions. Lower dislocation densities, $N_{\text {ed }}$ and $N_{\text {scw }}$, a lower surface roughness, and a slightly higher mobility and a lower LPP broadening for the N-rich (B7) with respect to the In-rich (B8) InN were found. We attribute these better structural and transport properties of $\mathrm{B} 7$ to the adjusted growth conditions better suited for N-polar InN. Interestingly, the heavily doped sample B7, grown under N-rich conditions has similar structural properties to the undoped InN (see Table I). This indicates that adjusting growth conditions after polarity inversion may offer a pathway to the growth of compensated $\mathrm{InN}$ material with relatively high mobility and good crystal quality.

\section{Lattice parameters}

Figures 9(a) and 9(b) show the measured $a$ and $c$ lattice parameters of the InN films from both sets as a function of $\mathrm{Mg}$ concentration. It is seen that the $a$ lattice parameter increases while the $c$ lattice parameter decreases with increasing $\mathrm{Mg}$ concentration.

Several types of strain are present in the InN:Mg films: (i) strain due to the size effect from the incorporation of $\mathrm{Mg}$ in the InN host lattice; (ii) thermal biaxial strain due to the difference in thermal expansion coefficients of sapphire and InN; (iii) biaxial strain due to the lattice mismatch between $\mathrm{GaN}$ and InN; and (iv) growth strain associated with the specific growth mode, grain coalescence, etc.

$\mathrm{Mg}$ occupies the In site in the crystal lattice of $\mathrm{InN}$ doped with Mg. ${ }^{5}$ We have shown very recently by first principle calculations that the incorporation of $\mathrm{Mg}$ leads to decrease of $c$ and $a$ lattice parameters as a result of the size effect with ${ }^{67}$

$$
\frac{a_{\mathrm{InN}: \mathrm{Mg}}-a_{\mathrm{InN}}}{a_{\mathrm{InN}}}=\frac{c_{\mathrm{InN}: \mathrm{Mg}}-c_{\mathrm{InN}}}{c_{\mathrm{InN}}}=\beta_{\text {size }}[M g],
$$

where $\beta_{\text {size }}=-1.2 \times 10^{24} \mathrm{~cm}^{-3}$. For instance, if we consider the $p$-type range of $\mathrm{Mg}$ concentrations we would expect that the changes in lattice parameters due to the size effect would be $\Delta a=-0.0004 \AA$ and $\Delta c=-0.0006 \AA$, for the upper end of the window $\left([\mathrm{Mg}]=9.0 \times 10^{19} \mathrm{~cm}^{-3}\right)$. It is seen from
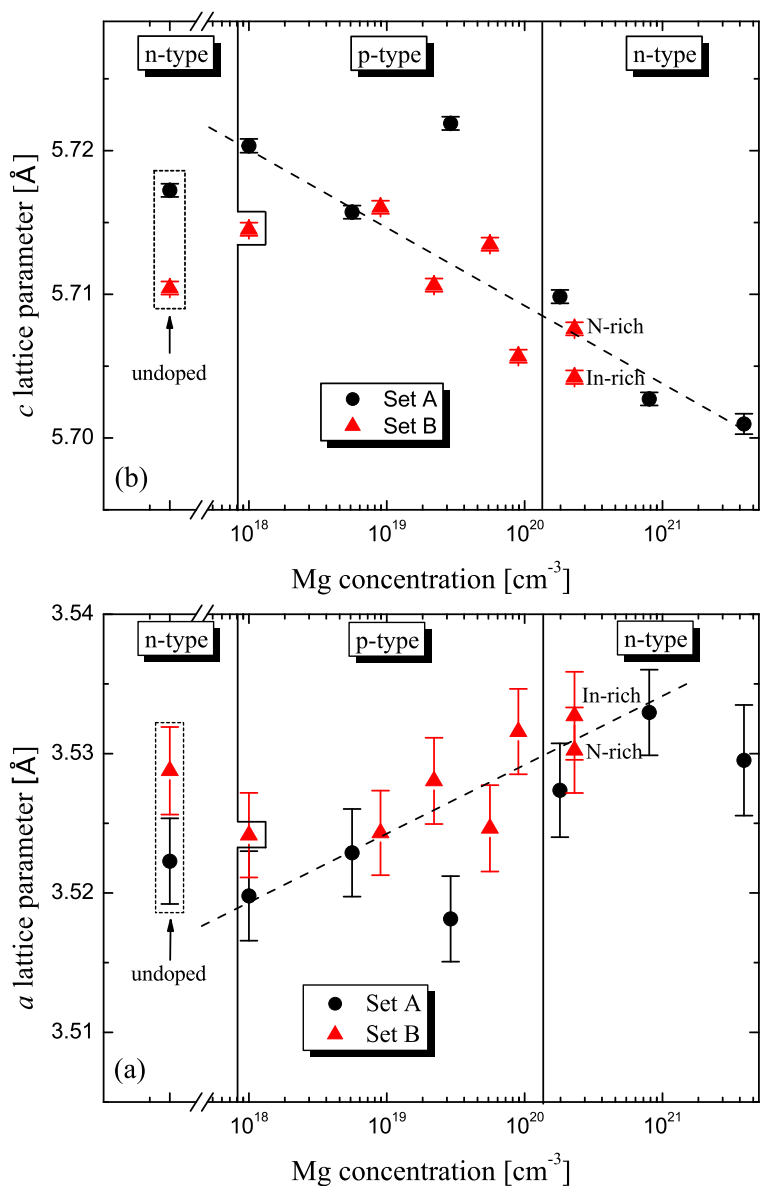

FIG. 9. Measured $a$ (a) and $c$ (b) lattice parameters of the InN films from the two sets as function of $\mathrm{Mg}$ concentration. 
Fig. 9 that the $a$ lattice parameter in this range of $\mathrm{Mg}$ concentrations instead increases with more than $0.007 \AA$ and the $c$ lattice parameter decreases with more than $0.01 \AA$. As another example, one can take the sample with the highest $[\mathrm{Mg}]=3.9 \times 10^{21} \mathrm{~cm}^{-3}$, for which the size effect predicts a decrease in the lattice parameters of $-0.001 \AA$. This estimate is incompatible with the experimental values of $+0.02 \AA$ for $a$ and $-0.02 \AA$ for $c$, respectively. Obviously the trend observed in the measured lattice parameters cannot be explained by the size effect due to $\mathrm{Mg}$ incorporation.

The thermal in-plane strain in $\mathrm{InN}$ is expected to be compressive and it should be the same for the samples from a given set. The in-plane lattice parameter of the GaN buffer layer, $a_{\mathrm{GaN}}=3.1893 \AA^{45}$ is smaller than the one of $\mathrm{InN}$, $a_{\mathrm{InN}}=3.539 \AA^{68}$ and the resulting lattice mismatch will also cause compressive in-plane strain. Therefore, the biaxial strain component cannot lead to the observed increase in the $a$-lattice parameter of InN either.

Therefore, we suggest that the increase of the $a$-lattice parameter with $\mathrm{Mg}$ concentration is related to the growth strain. It is known that during the coalescence of grains, a tensile biaxial strain in the film could be generated. ${ }^{69}$ Tensile biaxial growth strain caused by the incorporation of $\mathrm{Mg}$ in InN provides an explanation for the observed trend of increasing $a$ and decreasing $c$-lattice parameters (see Fig. 9). The resulting total stress in the films remains compressive due to the differences in thermal expansion coefficients of substrate and film, which overwhelms the tensile growth stress. Similar findings are reported for Si-doped GaN grown on sapphire, for which the silicon incorporation was shown to cause generation of tensile growth stress in the films. ${ }^{70}$

\section{CONCLUSIONS}

In conclusion, we have studied the effect of $\mathrm{Mg}$ doping on the FCC and structural properties of two different sets of InN films grown by MBE. A systematic change of the type of free-charge carriers and their parameters was found with increasing [Mg]: (i) low-doped InN:Mg with $n$-type conductivity for $[\mathrm{Mg}] \leqq 1.0 \times 10^{18} \mathrm{~cm}^{-3}$; (ii) a $p$-type window of InN: $\mathrm{Mg}$ showing free holes in the low $10^{18} \mathrm{~cm}^{-3}$ range for $1.0 \times 10^{18} \mathrm{~cm}^{-3} \lesssim[\mathrm{Mg}] \leqq 9.0 \times 10^{19} \mathrm{~cm}^{-3}$; and (iii) heavily doped $\mathrm{InN}: \mathrm{Mg}$ in which the conductivity type has switched again to $n$ for $[\mathrm{Mg}] \gtrsim 1.8 \times 10^{20} \mathrm{~cm}^{-3}$. The structural parameters and extended defect densities in the InN films from the low-doped range and the $p$-type window are not affected by the $\mathrm{Mg}$ doping and remain very similar to those of undoped InN. These films further exhibit smooth surfaces and dislocation pinned step-flow growth morphology typical for high-quality In-polar InN epitaxial layers. On the other hand, the surfaces of the heavily doped $\mathrm{InN}: \mathrm{Mg}$ films roughen significantly and reveal columnar-like growth. This is accompanied with an increase in screw dislocation density and deterioration of structural quality that is attributed to inversion of InN polarity. It is suggested that $\mathrm{Mg}$ incorporation leads to the generation of stacking faults, the density of which increases with increasing $[\mathrm{Mg}]$ and eventually leads to the formation of $\mathrm{ZB}-\mathrm{InN}$. The $\mathrm{ZB}-\mathrm{InN}$ volume fraction was shown to scale linearly with $\mathrm{Mg}$ concentration for the heavily doped InN films. Similar trends of increasing free electron concentration, density of screw type dislocations, and $\mathrm{ZB}$ InN volume fraction with increasing $[\mathrm{Mg}]$ were observed for the heavily doped InN films. However, a comparison between the structural characteristics and free electron concentrations of InN films doped with the same $[\mathrm{Mg}]$ but grown under different conditions suggests a complex interplay between extended and point defects for the $n$-type conductivity in InN. It was also suggested that adjusting growth conditions towards more $\mathrm{N}$-rich regime after polarity inversion may offer a pathway to the growth of compensated InN material with relatively high mobility and good crystal quality. Finally, the incorporation of $\mathrm{Mg}$ was found to cause an increase of the $a$ - and decrease of the $c$-lattice parameters, which was attributed to a Mg-induced growth strain of tensile biaxial nature.

\section{ACKNOWLEDGMENTS}

We acknowledge support from the Swedish Research Council (VR) under Grant No. 2013-5580, the Swedish Governmental Agency for Innovation Systems (VINNOVA) under the VINNMER international qualification program, Grant No. 2011-03486, and the Swedish Foundation for Strategic Research (SSF), Grant No. FFL12-0181. The authors further acknowledge grant support by U.S. Army Research Office under Award W911NF-09-C-0097, the National Science Foundation under Awards MRSEC DMR0820521, MRI DMR-0922937, DMR-0907475, ECCS0846329, and EPS-1004094, by the University of NebraskaLincoln, the J. A. Woollam Co., Inc., and the J. A. Woollam Foundation.

${ }^{1}$ J. Wu, J. Appl. Phys. 106, 011101 (2009).

${ }^{2}$ P. D. C. King, T. D. Veal, P. H. Jefferson, S. A. Hatfield, L. F. J. Piper, C. F. McConville, F. Fuchs, J. Furthmüller, F. Bechstedt, H. Lu, and W. J. Schaff, Phys. Rev. B 77, 045316 (2008).

${ }^{3}$ W. Walukiewicz, Physica B 302-303, 123 (2001).

${ }^{4}$ A. Janotti and C. G. Van de Walle, Appl. Phys. Lett. 92, 032104 (2008).

${ }^{5}$ X. M. Duan and C. Stampfl, Phys. Rev. B 79, 035207 (2009).

${ }^{6}$ G. Koblmüller, C. S. Gallinat, S. Bernardis, J. S. Speck, G. D. Chern, E. D. Readinger, H. Shen, and M. Wraback, Appl. Phys. Lett. 89, 071902 (2006).

${ }^{7}$ A. Yoshikawa, S. Che, Y. Ishitani, and X. Wang, J. Cryst. Growth 311, 2073 (2009).

${ }^{8}$ N. Miller, E. E. Haller, G. Koblmüller, C. Gallinat, J. S. Speck, W. J. Schaff, M. E. Hawkridge, K. M. Yu, and J. W. Ager, Phys. Rev. B 84, 075315 (2011).

${ }^{9}$ V. Darakchieva, K. Lorenz, M.-Y. Xie, E. Alves, W. J. Schaff, T. Yamaguchi, Y. Nanishi, S. Ruffenach, M. Moret, and O. Briot, Phys. Status Solidi A 209, 91 (2012).

${ }^{10}$ X. Q. Wang, S. Liu, N. Ma, L. Feng, G. Chen, F. Xu, N. Tang, S. Huang, K. J. Chen, S. Zhou, and B. Shen, Appl. Phys. Express 5, 015502 (2012).

${ }^{11}$ T. Dietl, H. Ohno, and F. Matsukura, Phys. Rev. B 63, 195205 (2001).

${ }^{12}$ H. Lu, W. J. Schaff, L. F. Eastman, and C. E. Stutz, Appl. Phys. Lett. 82, 1736 (2003).

${ }^{13}$ I. Mahboob, T. D. Veal, C. F. McConville, H. Lu, and W. J. Schaff, Phys. Rev. Lett. 92, 036804 (2004).

${ }^{14}$ C. H. Swartz, R. P. Tompkins, N. C. Giles, T. H. Myers, H. Lu, W. J. Schaff, and L. F. Eastman, J. Cryst. Growth 269, 29 (2004).

${ }^{15}$ C. S. Gallinat, G. Koblmüller, J. S. Brown, S. Bernardis, J. S. Speck, G. D. Chern, E. D. Readinger, H. Shen, and M. Wraback, Appl. Phys. Lett. 89, 032109 (2006). 
${ }^{16}$ V. Darakchieva, T. Hofmann, M. Schubert, B. E. Sernelius, B. Monemar, P. O. A. Persson, F. Giuliani, E. Alves, H. Lu, and W. J. Schaff, Appl. Phys. Lett. 94, 022109 (2009).

${ }^{17}$ V. Darakchieva, K. Lorenz, N. P. Barradas, E. Alves, B. Monemar, M. Schubert, N. Franco, C. L. Hsiao, W. J. Schaff, L. W. Tu, T. Yamaguchi, and Y. Nanishi, Appl. Phys. Lett. 96, 081907 (2010).

${ }^{18}$ R. E. Jones, K. Yu, S. X. Li, W. Walukiewicz, J. Ager, E. Haller, H. Lu, and W. Schaff, Phys. Rev. Lett. 96, 125505 (2006).

${ }^{19}$ J. H. Chai, Y.-W. Song, R. J. Reeves, and S. M. Durbin, Phys. Status Solidi A 209, 95 (2012).

${ }^{20}$ J. H. Chai, T. H. Myers, Y.-W. Song, R. J. Reeves, W. M. Linhart, R. J. H. Morris, T. D. Veal, M. G. Dowsett, C. F. McConville, and S. M. Durbin, J. Vac. Sci. Technol. B 30, 02B124 (2012).

${ }^{21}$ M. Himmerlich, A. Knübel, R. Aidam, L. Kirste, A. Eisenhardt, S. Krischok, J. Pezoldt, P. Schley, E. Sakalauskas, R. Goldhahn, R. Félix, J. M. Mánuel, F. M. Morales, D. Carvalho, T. Ben, R. García, and G. Koblmüller, J. Appl. Phys 113, 033501 (2013).

${ }^{22}$ X. Wang, S. B. Che, Y. Ishitani, and A. Yoshikawa, Appl. Phys. Lett. 91, 242111 (2007).

${ }^{23}$ K. Wang, N. Miller, R. Iwamoto, T. Yamaguchi, M. A. Mayer, T. Araki, Y. Nanishi, K. M. Yu, E. E. Haller, W. Walukiewicz, and J. W. Ager, Appl. Phys. Lett. 98, 042104 (2011).

${ }^{24}$ N. Miller, J. W. Ager III, H. M. Smith III, M. A. Mayer, K. M. Yu, E. E. Haller, W. Walukiewicz, W. J. Schaff, C. Gallinat, G. Koblmuller, and J. S. Speck, J. Appl. Phys. 107, 113712 (2010).

${ }^{25}$ O. Bierwagen, S. Choi, and J. S. Speck, Phys. Rev. B 85, 165205 (2012).

${ }^{26}$ P. A. Anderson, C. H. Swartz, D. Carder, S. M. Durbin, S. Chandril, and T. H. Myers, Appl. Phys. Lett. 89, 184104 (2006).

${ }^{27}$ N. Ma, X. Q. Wang, F. J. Xu, N. Tang, B. Shen, Y. Ishitani, and A. Yoshikawa, Appl. Phys. Lett. 97, 222114 (2010).

${ }^{28}$ M. Fujiwara, Y. Ishitani, X. Wang, S. Che, and A. Yoshikawa, Appl. Phys. Lett. 93, 231903 (2008)

${ }^{29}$ S. Schoche, T. Hofmann, V. Darakchieva, N. B. Sedrine, X. Wang, A. Yoshikawa, and M. Schubert, J. Appl. Phys. 113, 013502 (2013).

${ }^{30}$ X. Wang, S. B. Che, Y. Ishitani, A. Yoshikawa, H. Sasaki, T. Shinagawa, and S. Yoshida, Appl. Phys. Lett. 91, 081912 (2007).

${ }^{31}$ Y. Nanishi, T. Araki, and T. Yamaguchi, in Indium Nitride and Related Alloys, edited by T. D. Veal, C. F. McConville, and W. J. Schaff (CRC Press, Taylor and Francis Group, Boca Raton, 2010), p. 28.

${ }^{32} \mathrm{X}$. Q. Wang and A. Yoshikawa, in Indium Nitride and Related Alloys, edited by T. Veal, C. McConville, and W. Schaff (CRC Press, Taylor and Francis Group, Boca Raton, 2010), p. 83.

${ }^{33}$ A. Yoshikawa, X. Wang, Y. Ishitani, and A. Uedono, Phys. Status Solidi A 207, 1011 (2010).

${ }^{34}$ Z. Liliental-Weber, M. E. Hawkridge, X. Wang, and A. Yoshikawa, Phys. Status Solidi C 7(7-8), 2025 (2010).

${ }^{35}$ A. Uedono, H. Nakamori, K. Narita, J. Suzuki, X. Wang, S.-B. Che, Y. Ishitani, A. Yoshikawa, and S. Ishibashi, J. Appl. Phys. 105, 054507 (2009).

${ }^{36}$ S. Choi, F. Wu, O. Bierwagen, and J. S. Speck, J. Vac. Sci. Technol. A 31, 031504 (2013).

${ }^{37}$ T. Yamaguchi and Y. Nanishi, Appl. Phys. Express 2, 051001 (2009).

${ }^{38}$ H. Fujiwara, Spectroscopic Ellipsometry (John Wiley \& Sons, New York, 2007).

${ }^{39}$ M. Schubert, T. E. Tiwald, and C. M. Herzinger, Phys. Rev. B 61, 8187 (2000).

${ }^{40}$ A. Kasic, M. Schubert, S. Einfeldt, D. Hommel, and T. Tiwald, Phys. Rev. B 62, 7365 (2000)

${ }^{41}$ V. Darakchieva, Phys. Status Solidi A 205, 905 (2008).

${ }^{42}$ V. Darakchieva, P. P. Paskov, E. Valcheva, T. Paskova, B. Monemar, M. Schubert, H. Lu, and W. J. Schaff, Appl. Phys. Lett. 84, 3636 (2004).
${ }^{43}$ V. Darakchieva, T. Paskova, M. Schubert, H. Arwin, P. P. Paskov, B. Monemar, D. Hommel, M. Heuken, J. Off, F. Scholz, B. Haskell, P. Fini, J. Speck, and S. Nakamura, Phys. Rev. B 75, 195217 (2007).

${ }^{44}$ A. A. Kukharskii, Solid State Commun. 13, 1761 (1973).

${ }^{45}$ V. Darakchieva, B. Monemar, and A. Usui, Appl. Phys. Lett. 91, 031911 (2007).

${ }^{46}$ M.-Y. Xie, M. Schubert, J. Lu, P. O. A. Persson, F. Giuliani, C. L. Hsiao, L. C. Chen, W. J. Schaff, and V. Darakchieva, "Structural, free-charge carrier and phonon properties of zinc-blende and wurtizte InN polymorphs in mixed-phase InN epitaxial layers," Phys. Rev. B (unpublished).

${ }^{47}$ T. Metzger, R. Höpler, E. Born, O. Ambacher, M. Stuzmann, R. Stömmer, M. Schuster, H. Göbel, S. Chriastiansen, M. Albrecht, and H. P. Strunk, Philos. Mag. A 77, 1013 (1998).

${ }^{48}$ V. Srikant, J. S. Speck, and D. R. Clarke, J. Appl. Phys. 82, 4286 (1997).

${ }^{49}$ T. Hofmann, V. Darakchieva, B. Monemar, H. Lu, W. J. Schaff, and M. Schubert, J. Electron. Mater. 37, 611 (2008).

${ }^{50} \mathrm{X}$. Wang, S. B. Che, Y. Ishitani, and A. Yoshikawa, Appl. Phys. Lett. 92, 132108 (2008).

${ }^{51}$ N. Ma, X. Q. Wang, S. T. Liu, G. Chen, J. H. Pan, L. Feng, F. J. Xu, N. Tang, and B. Shen, Appl. Phys. Lett. 98, 192114 (2011).

${ }^{52}$ B. Heying, R. Averback, L. F. Chen, E. Haus, H. Riechert, and J. S. Speck, J. Appl. Phys. 88, 1855 (2000).

${ }^{53}$ E. Dimakis, E. Iliopoulos, K. Tsagaraki, T. Kehagias, P. Komininou, and A. Georgakilas, J. Appl. Phys. 97, 113520 (2005).

${ }^{54}$ X. Wang, S. B. Che, Y. Ishitani, and A. Yoshikawa, Jpn. J. Appl. Phys., Part 2 45, L730 (2006).

${ }^{55}$ C. S. Gallinat, G. Koblmüller, J. S. Brown, and J. S. Speck, J. Appl. Phys. 102, 064907 (2007).

${ }^{56} \mathrm{X}$. Wang, S. B. Che, Y. Ishitani, and A. Yoshikawa, J. Appl. Phys. 99, 073512 (2006).

${ }^{57}$ G. Koblmüller, C. S. Gallinat, and J. S. Speck, J. Appl. Phys. 101, 083516 (2007).

${ }^{58}$ R. Chierchia, T. Böttcher, H. Heinke, S. Einfeldt, S. Figge, and D. Hommel, J. Appl. Phys. 93, 8918 (2003).

${ }^{59}$ V. Darakchieva, J. Birch, M. Schubert, T. Paskova, S. Tungasmita, G. Wagner, A. Kasic, and B. Monemar, Phys. Rev. B 70, 045411 (2004).

${ }^{60}$ V. Darakchieva, K. Lorenz, M. Y. Xie, E. Alves, C. L. Hsiao, L. C. Chen, L.-W. Tu, T. Yamaguchi, and Y. Nanishi, J. Appl. Phys. 110, 063535 (2011).

${ }^{61}$ X. Wang, S.-B. Che, Y. Ishitani, and A. Yoshikawa, Appl. Phys. Lett. 90, 151901 (2007).

${ }^{62}$ C. S. Gallinat, G. Kolbmüller, and J. S. Speck, in Indium Nitride and Related Alloys, edited by T. Veal, C. McConville, and W. Schaff (CRC Press, Taylor and Francis Group, Boca Raton, 2010), p. 51.

${ }^{63}$ L. F. J. Piper, T. D. Veal, C. F. McConville, H. Lu, and W. J. Schaff, Appl. Phys. Lett. 88, 252109 (2006).

${ }^{64}$ V. Cimalla, V. Lebedev, F. M. Morales, R. Goldhahn, and O. Ambacher, Appl. Phys. Lett. 89, 172109 (2006).

${ }^{65}$ C. S. Gallinat, G. Koblmüller, and J. S. Speck, Appl. Phys. Lett. 95, 022103 (2009).

${ }^{66}$ M. Imura, S. Tsuda, T. Nagata, H. Takeda, M. Y. Liao, A. L. Yang, Y. Yamashita, H. Yoshikawa, Y. Koide, K. Kobayashi, T. Yamaguchi, M. K. a. N. Uematsu, K. Wang, T. Araki, and Y. Nanishi, Appl. Phys. Lett. 103, 162110 (2013).

${ }^{67}$ M.-Y. Xie, PhD thesis, ISBN:978-91-7519-754-8, LiU Tryck, Linköping (2012).

${ }^{68}$ V. Darakchieva, M.-Y. Xie, F. Tasnádi, I. A. Abrikosov, L. Hultman, B. Monemar, J. Kamimura, and K. Kishino, Appl. Phys. Lett. 93, 261908 (2008).

${ }^{69}$ S. Raghavan, J. Acord, and J. M. Redwing, Appl. Phys. Lett. 86, 261907 (2005).

${ }^{70}$ L. T. Romano, C. G. Van de Walle, J. W. Ager III, W. Götz, and R. S. Kern, J. Appl. Phys. 87, 7745 (2000). 